\title{
Mars from the InSight Out
}

There's a seismometer on Mars, and it's been busy! With more than 700

marsquakes detected so far, scientists have a clearer picture of the interior structure of Mars than they ever had before. That picture shows that Mars has a liquid metal core, a thick mantle with a rocky layer above a more fluid layer, and a crust that is proportionally thicker than Earth's.

The seismometer on Mars, called Seismic Experiment for Interior Structure (SEIS), is part of NASA's Interior Exploration using Seismic Investigations, Geodesy and Heat Transport (InSight) lander. The quakes SEIS can detect are subtler than those detectable on Earth because Mars is free of the seismic noise generated by Earth's oceans and thicker atmosphere. The instrument has been monitoring Mars for quakes since it landed in November 2018.

When seismic waves travel from their points of origin to a seismometer on the surface, the ways they reflect and bend reveal the interior structure of a planet. "What we're looking for is an echo," said Amir Khan of ETH Zürich. "We're detecting a direct sound-the quake-and then listening for an echo off a reflector deep underground." Every new quake is another brushstroke that paints a portrait of a planet's interior.

Mars's core is $54 \%$ of the total radius of the planet, and its mantle is $45 \%$. These are about the same proportions as Earth's. Mars's crust, however, is thicker relative to its planetary radius: Mars's is $1 \%$, and Earth's is $0.5 \%$.
Nearly all of the marsquakes detected so far have come from the Cerberus Fossae region about 1,600 kilometers away from the detector. The region was volcanically active in the past few million years. One quake, detected 18 September, came from somewhere unknown, 8,500 kilometers away.
"It took scientists hundreds of years to measure Earth's core; after the Apollo missions, it took them 40 years to measure the Moon's core. InSight took just 2 years to measure Mars's core." - Simon Stähler, ETH Zürich
After dusting off its solar panels, InSight detected its strongest marsquakes yet: quakes of magnitudes 4.1 and 4.2 on 18 September. The 18 September quake lasted for 1.5 hours. 